${ }^{13}$ Asamer, H, et al, Schweizerische medizinische Wochenschrift, 1974, 104, 1188 .

14 Evans, D J, et al, British Medical Fournal, 1973, 3, 326.

15 Garcia-Fuentes, M, Chantler, C, and Williams, D G, Tenth European Society for Paediatric Nephrology. Barcelona, Sandoz, 1976.

${ }^{16}$ Ashton, H, Frenk, E, and Stevenson, C J, British fournal of Dermatology, $1971,85,199$.

17 Sterky, G, and Thilén, A, Acta Paediatrica, 1960, 49, 217.

18 Koskimies, O, et al, Acta Paediatrica Scandinavica, 1974, 63, 357.

19 Winterborn, M H, personal communication.

20 Medical Research Council Working Party, British Medical fournal, 1971, 2, 239.

\section{Deafness and mental health}

The deaf or hard of hearing whose impairment arises after normal speech development are a neglected group. Their needs often go unrecognised and their disability may attract social stigma rather than sympathy. ${ }^{1}$ To a greater or less degree they may be isolated from past pleasures and present social discourse. ${ }^{2}{ }^{3}$ Difficulties in communication may result in their being bypassed or ignored even in matters of direct personal concern, so that they are made to feel stupid, inferior, or incompetent. Depression and other neurotic symptomsparticularly preoccupation with tinnitus or other adventitious noises-and various psychosomatic complaints are common sequelae, ${ }^{45}$ and many authors have drawn attention to the association between deafness and the development of paranoid illness. Kraepelin ${ }^{6}$ observed the occurrence of delusions of persecution in the hard of hearing, and more recent authors have emphasised the increased prevalence of deafness in schizophrenic and paranoid illnesses when compared with affective disorders. ${ }^{7}{ }^{9}$ Kay et $a l^{10}$ have shown that the presence of social deafness is one of the premorbid characteristics which discriminate between patients with paranoid and with affective psychoses.

Roth and McClelland ${ }^{11}$ contrasted patients with affective disorders with schizophrenics, who were found more often to have deafness, visual defects, or skeletal abnormalities such as dwarfism, hunchback, or amputations. They suggested that in predisposed individuals these disabilities might increase sensitivity, impede social communication and relationships, decrease self-esteem, and aggravate tendencies to withdrawal, solitariness, and paranoid distortion of reality. Misunderstanding or misinterpretation of the outside world may lead any of us to flashes of paranoid thinking, but the testing of these ideas against external reality offers constant readjustment. Where there is a failure of such reality testing an edifice of paranoid disorder may be erected upon this foundation of misunderstanding. ${ }^{12}$ It is not difficult to understand how deafness might facilitate such a process. Indeed, it is now apparent that deafness may contribute to the development of mental disorder through its association with sensory deprivation, communication disorder, perceptual distortion, and attention deficit or as a non-specific stress. ${ }^{13}$

Regardless of the actual pathogenesis, then, hearing disorders which are severe, of early onset, and of long duration are important causative factors in paranoid psychoses of middle and later life. In contrast, the hearing losses associated with ageing seem to be of less importance. This suggests that the psychopathological process is one of gradual change and offers some prospect of intervention. The commonest cause of the progression from deafness to paranoia is bilateral middle ear disease originating in childhood or early adult life, and here prevention should be the aim. Chronic suppurative otitis media tends to arise from multiple attacks of acute otitis media and otorrhoea, particularly in socially disadvantaged children. ${ }^{14}$ Education needs to be directed to early recognition and effective treatment, and more aggressive measures may be required to identify those at risk. Once deafness is established accurate assessment is essential, as is the prescription (where appropriate) of a flexible, effective, inconspicuous, and simple deaf aid. At present such aids are often cumbersome or unreliable, and the deaf tend to avoid wearing them or spend their money in search of more acceptable devices. ${ }^{15}$

Equally important are efforts to combat withdrawal or isolation by involvement of the deaf not only in organisations concerned specifically with the deaf, but also in more general social activities. Families and employers may need help and guidance, which can often be provided by social workers with special experience or through voluntary agencies. Assessment facilities, audiology services, and social services do, however, vary from one part of the country to another. The general practitioner has a vital part to play in ensuring that his patient receives the best service available and is enabled to remain in the real world.

${ }^{1}$ Barker, R G, Adjustment to Physical Handicap and Illness. New York, Social Science Research Council, 1953.

${ }^{2}$ Ashley, J, fourney into Silence. London, Bodley Head, 1973.

${ }^{3}$ Disabilities and How to Live With Them, p 10. London, Lancet, 1952.

${ }^{4}$ Denmark, J C, Proceedings of the Royal Society of Medicine, 1969, 62, 965.

5 Mahapatra, S B, Acta Psychiatrica Scandinavica, 1974, 50, 596.

${ }^{6}$ Kraepelin, E, Lehrbuch der Psychiatrie, 8th edn, vol 4, p 1441. Leipzig, Barth, 1915

Kay, D W K, and Roth, M, Fournal of Mental Science, 1961, 107, 649.

${ }^{8}$ Post, F, Persistent Persecutory States of the Elderly. London, Pergamon, 1966.

${ }^{9} \mathrm{McClelland}, \mathrm{H} \mathrm{A}$, et al, Proceedings of the Fourth World Congress of Psychiatry, vol 4, p 2955. London, Excerpta Medica, 1966.

${ }^{10}$ Kay, D W K, et al, British fournal of Psychiatry, 1976, 129, 207.

1 Roth, M, and McClelland, H A, Vestnik Academicheskikh Nauk SSSR, Meditsina, 1971, no 5, 77 .

12 Cameron, N, American fournal of Sociology, 1943, 49, 32.

${ }^{13}$ Cooper, A F, British Fournal of Psychiatry, 1976, 129, 216.

${ }_{14}$ Miller, F J W, et al, Growing up in Newcastle upon Tyne. London, Nuffield Foundation, Oxford University Press, 1960.

${ }^{15}$ British Medical fournal, 1973, 2, 569.

\section{Radiation-induced breast cancer}

There is no way in which a naturally occurring breast cancer can be distinguished histologically from one induced by ionising radiation. That radiation does induce breast cancer can, indeed, be suggested only by epidemiological data showing an increase in the observed incidence of the tumour in women at risk compared with that expected.

In 1965 MacKenzie $^{1}$ reported an increase of breast cancer in women who had had repeated fluoroscopic examinations during treatment by artificial pneumothorax for pulmonary tuberculosis. Myrden and Hiltz ${ }^{2}$ continued this investigation among tuberculous women in Nova Scotia. Of 300 women fluoroscoped, 22 developed cancer of the breast compared with 4 of the 483 who had not undergone fluoroscopy. The average age of the women at the time of irradiation was 26 , and the cancers developed about 17 years later. Some of the patients had had more than 500 fluoroscopies; the total dose of radiation to the breast varied from 50 rads to 6000 rads delivered over some weeks to years. In a separate type of study Wanebo et $a l^{3}$ noted an excess of breast cancer in women who had survived an 